\title{
Cancer associated fibroblasts: An essential role in the tumor microenvironment (Review)
}

\author{
LEILEI TAO, GUICHUN HUANG, HAIZHU SONG, YITIAN CHEN and LONGBANG CHEN \\ Department of Medical Oncology, Jinling Hospital, Medical School of Nanjing University, Nanjing, \\ Jiangsu 210002, P.R. China
}

Received October 24, 2015; Accepted May 8, 2017

DOI: $10.3892 / 01.2017 .6497$

\begin{abstract}
Fibroblasts in the tumor stroma are well recognized as having an indispensable role in carcinogenesis, including in the initiation of epithelial tumor formation. The association between cancer cells and fibroblasts has been highlighted in several previous studies. Regulation factors released from cancer-associated fibroblasts (CAFs) into the tumor microenvironment have essential roles, including the support of tumor growth, angiogenesis, metastasis and therapy resistance. A mutual interaction between tumor-induced fibroblast activation, and fibroblast-induced tumor proliferation and metastasis occurs, thus CAFs act as tumor supporters. Previous studies have reported that by developing fibroblast-targeting drugs, it may be possible to interrupt the interaction between fibroblasts and the tumor, thus resulting in the suppression of tumor growth, and metastasis. The present review focused on the reciprocal feedback loop between fibroblasts and cancer cells, and evaluated the potential application of anti-CAF agents in the treatment of cancer.
\end{abstract}

\section{Contents}

1. Introduction

2. General characteristics of CAFs

3. Tumors induce fibroblast activation

4. CAFs induce tumor growth, angiogenesis, metastasis and chemoresistance

5. Interaction loop

6. Inhibition of the feedback loop as an approach for anticancer therapy

7. Conclusion

Correspondence to: Dr Longbang Chen, Department of Medical Oncology, Jinling Hospital, Medical School of Nanjing University, 305 Zhongshan Eastern Road, Nanjing, Jiangsu 210002, P.R. China E-mail: drchenlb@nju.edu.cn

Key words: cancer associated fibroblasts, cancer, interaction, loop, therapy

\section{Introduction}

Tumors that comprise a mass of malignant epithelial cells are also surrounded by multiple non-cancerous cell populations, including fibroblasts, endothelial cells, pericytes, immune regulatory cells and cytokines in the extracellular matrix (ECM) (1). These stromal cells surrounding the tumor form a distinct microenvironment and were not considered to possess a role in cancer progression. However, it became evident that the molecular and biological abnormalities of cancer cells could not fully explain the complex changes involved in the regulation of tumor progression (2). Thus, an increasing number of studies have focused on the functions of the tumor microenvironment in cancer progression (3-5).

Activated fibroblasts, termed cancer-associated fibroblasts (CAFs), are one of the major components of stromal cells. CAFs were first identified as negative factors in tumor development that had no effect on tumor cells; however, they have been identified as an essential component in tumor progression (6). With the reciprocal crosstalk between cancer cells and fibroblasts, CAFs undergo various morphological and biological transitions in response to tumor progression (7). Furthermore, CAFs have an important role in maintaining an optimal microenvironment for cancer cell survival and proliferation $(6,7)$. Studies investigating the role of CAFs have reported that the therapeutic targeting of cancer cells alone is insufficient for the treatment of cancer (8). Thus, cancer therapy should co-target cancer cells and their microenvironment. CAFs are essential components to the tumor microenvironment and therefore represent a molecular target for the treatment of cancer (9).

The present study is a review of the recent developments in CAF research, and is aimed at gaining an improved understanding of the biological mechanisms underlying CAF involvement in tumor progression. Furthermore, the association between cancer cells and the tumor microenvironment was analyzed in order to identify novel strategies for the treatment of cancer.

\section{General characteristics of CAFs}

CAFs are a heterogeneous population of cells with various origins, the majority of which are derived from resident fibroblasts. CAFs may also be derived from other cells, including mesenchymal stem cells (MSCs), epithelial, pericytes, 
adipocytes and endothelial cells (10). CAFs in the tumor stroma can be differentiated according to their morphology and specific identifiable markers. CAFs are generally presented as large spindle-shaped cells similar to smooth muscle cells (myofilaments and electron dense patches) (11). $\alpha$-smooth muscle actin is regarded as the most widely used biomarker for identifying CAFs (12). Fibroblast activation protein $\alpha$ (FAP $\alpha$ ) is a cytomembrane protein that is selectively expressed by activated CAFs in various types of human epithelial cancer (13). Furthermore, podoplanin-a, S100A4, vimentin, fibroblast specific protein-1 (FSP-1), and platelet-derived growth factor (PDGF) receptors $\alpha$ and $\beta$ are expressed in CAFs (14). Insulin-like growth factor-binding protein 7 (IGFBP7), a novel biomarker for tumor fibroblasts in epithelial cancer, has also been detected in CAFs through genetic screenings and immunohistochemical studies. IGFBP7-expressing CAFs have been demonstrated to promote colon cancer cell proliferation through paracrine tumor-stroma interactions in vitro (15).

The application of microarray gene-expression analysis has enabled the comprehensive characterization of CAFs and has increased awareness on the importance of CAFs in oncological studies. A total of 46 differentially expressed genes regulated by the transforming growth factor (TGF)- $\beta$ signaling pathway were identified in 15 paired CAF and normal fibroblast (NF) cell lines (16). All 46 genes were identified to encode for paracrine factors that are released into the tumor microenvironment. Of these results, 11 genes [intercellular-adhesion molecule 1 (ICAM1), THBS2, MME, OXTR, PDE3B, B3GALT2, EVI2B, COL14A1, GAL and MCTP2] were used to form a prognostic signature of CAFs in non-small cell lung cancer (NSCLC) (16). Similar studies have identified differentially-expressed genes between CAFs and NFs (17-20). Integrin $\alpha 11$ was identified to be primarily expressed in CAFs and possess prognostic significance for NSCLC (17). Furthermore, cyclooxygenase 2 and TGF- $\beta 2$ expression in CAFs was confirmed through immunohistochemical analysis in metastatic colon cancer (18). In human primary pancreatic adenocarcinoma, smoothened homolog was identified to be overexpressed in CAFs compared with the expression in pancreatic NFs (19). In addition, numerous altered gene transcripts have been identified in breast CAFs, including that of ribsosomal protein S6 kinase $\alpha 3$, fibroblastic growth factor (FGF) receptor 1, nardilysin that enhances shedding of EGF (NRD1), cyclin-dependent kinase inhibitor 1B, NFY and prostaglandin E synthase 2 (20). However, no significant differences in the gene expression pattern of NFs were reported with the most upregulated gene being chromobox 2, a polycomb homolog repressor of proto oncogenes (20).

\section{Tumors induce fibroblast activation}

When cancer cells metastasize to another organ, they recruit NFs to the tumor mass. The activated phenotype of fibroblasts in the tumor mass are induced by different genetic and epigenetic changes that are self-regulated, and regulated by cancer cells; however, the mechanisms underlying the transformation of NFs to CAFs remains unclear (21).

The activation of fibroblasts is induced by numerous cytokines secreted by cancer cells and other stroma cells, including TGF- $\beta$, epidermal growth factor (EGF), PDGF, FGF2 and
C-X-C motif chemokine ligand (CXCL) 12 (22). Cell-cell communication through adhesion molecules, including ICAM1 and vascular-cell adhesion molecule 1 also enables fibroblast activation (23).

MicroRNAs (miRNAs/miRs) are an abundant type of endogenous small RNA molecule that downregulate target gene expression (24). A previous study demonstrated that miR-155 is upregulated, whereas miR-31 and miR-214 are downregulated in ovarian CAFs (25). C-C motif chemokine ligand (CCL) 5 was identified as a target gene of miR-214. The results demonstrated that ovarian cancer cells induce the transformation of NFs to CAFs partially through regulation by miRNAs when NFs are co-cultured with cancer cells (25). These findings suggest that miRNAs have a regulatory role in the transformation of NFs to CAFs. Other miRNAs that have been identified to be differentially expressed in CAFs are listed in Table I (26-30).

\section{CAFs induce tumor growth, angiogenesis, metastasis and chemoresistance}

CAFs induce tumor growth. Tumor growth depends on the abnormal and uncontrollable proliferation of cancer cells with simultaneous changes to the microenvironment. Among the stromal cells in the microenvironment surrounding the tumor, increasing evidence has reported that CAFs are targets and inducers of tumorigenic activation signals $(31,32)$.

CAFs produce autocrine and/or paracrine cytokines that promote the biological characteristics of tumors. In addition to classical growth factors, including EGF and hepatocyte growth factor (HGF), novel CAF-secreted proteins [secreted frizzled related protein 1 , and IGF like family member (IGF) 1 and 2], and membrane molecules (integrin $\alpha 11$ and syndecan-1) have also been identified to possess cancer cell-supporting roles (33). These factors directly or indirectly stimulate tumor growth and survival, or enhance their migratory and invasive properties.

Previous studies have demonstrated that chemokines secreted by CAFs into the microenvironment allow for the recruitment of bone marrow-derived cells (BMCs) and immune cells (34). CXCL12 (35), CXCL14 (36) and CCL5 (37) have been identified as pro-metastatic factors. In addition, MSC-derived CAFs are recruited to the stroma of the dysplastic stomach, and express interleukin (IL)-6, Wnt family member (Wnt) $5 \alpha$ and bone morphogenetic protein 4 , all of which promote tumor growth through DNA hypomethylation (38). Furthermore, MSC-derived CAFs are recruited to the tumor through TGF- $\beta$ and CXCL12 signaling (38). In oral squamous cell carcinoma (OCC), CCL2 expression in CAFs is upregulated, promoting the production of endogenous reactive oxygen species (ROS) in OC cells (OCCs) (37). Consequently, ROS induces the expression of cell cycle regulatory proteins in OCCs, and promotes OCC proliferation, migration and invasion (39). Together, these chemokines and cytokines create a suitable microenvironment allowing for the proliferation and metastasis of cancer cells.

CAFs stimulate tumor angiogenesis. Vascular endothelial growth factor (VEGF) was originally identified as a multifunctional cytokine in angiogenesis and lymphangiogenesis (40). 
Table I. The regulation of miRNA in cancer associated fibroblasts.

A, Upregulated miRNAs

\begin{tabular}{|c|c|c|c|c|}
\hline Author, year & miRNA & Cancer type & Target gene & (Refs.) \\
\hline Mitra et al, 2012 & $\operatorname{miR}-155$ & Ovarian & & $(25)$ \\
\hline Zhao et al, 2012 & $\begin{array}{l}\text { miR-266, miR-221-3p, } \\
\text { miR-221-5p, miR-31-3p }\end{array}$ & Breast & ETS2 & (26) \\
\hline Enkelmann et al, 2011 & miR-16, miR-320 & Bladder & & (27) \\
\hline Aprelikova et al, 2014 & $\begin{array}{l}\text { miR-29b, miR-146a } \\
\text { miR-503 }\end{array}$ & Endometrial & & (29) \\
\hline Wang et al, 2013 & $\begin{array}{l}\operatorname{miR}-138, \operatorname{miR}-210 \\
\operatorname{miR}-99 a\end{array}$ & Colorectal & & $(30)$ \\
\hline Bronisz et al, 2012 & $\operatorname{miR}-320$ & Breast & & $(55)$ \\
\hline
\end{tabular}

B, Downregulated miRNAs

\begin{tabular}{|c|c|c|c|c|}
\hline Mitra et al, 2012 & miR-31 & Ovarian & SATB2 & $(25)$ \\
\hline Mitra et al, 2012 & $\operatorname{miR}-214$ & Ovarian & CCL5 & $(25)$ \\
\hline Zhao et al, 2012 & $\begin{array}{l}\operatorname{miR}-205, \text { miR-200c, } \\
\text { miR-200b, miR-141, } \\
\text { miR-101, miR-342-3p, } \\
\text { Let-7g }\end{array}$ & Breast & ZEB1/SIP1 & $(26)$ \\
\hline Enkelmann et al, 2011 & miR-143, miR-145 & Bladder & & $(27)$ \\
\hline Yu et al, 2010 & $\operatorname{miR}-17 / 20$ & Breast & IL-8, CXCL1, CK8, $\alpha-\mathrm{ENO}$ & $(28)$ \\
\hline Aprelikova et al, 2014 & $\operatorname{miR}-31$ & Endometrial & SATB2 & $(29)$ \\
\hline Wang et al, 2013 & $\begin{array}{l}\operatorname{miR}-29 b, \operatorname{miR}-494 \\
\operatorname{miR}-126\end{array}$ & Colorectal & & $(30)$ \\
\hline Verghese et al, 2013 & $\operatorname{miR}-26 b$ & Breast & TNKS1BP1, CPSF7, COL12A1 & $(54)$ \\
\hline Mongiat et al, 2010 & miR-15, miR-16 & Prostate & & $(56)$ \\
\hline
\end{tabular}

The interaction between tumor and stromal cells can result in increased VEGF expression, with CAFs being the primary source of VEGF (41). Furthermore, CAF-derived PDGF has been demonstrated to be an essential factor in activating VEGF production. PDGF/PDGF receptor $(\mathrm{R})$ signaling is an important regulatory pathway primarily involved in angiogenesis (41). PDGFs indirectly promote angiogenesis by recruiting stromal fibroblasts that secrete VEGF (42). Furthermore, PDGFs are able to recruit and induce BMCs to form endothelial or smooth muscle cells. Subsequently, PDGFs promote the proliferation and migration of endothelial, and smooth muscle cells (42). PDGF subunit B, which is produced by endothelial cells can induce the migration of pericytes to the vessel wall and maintain endothelial stability, thus leading to tumor angiogenesis (43).

Nagasaki et al (44) reported that cancer cells stimulate the secretion of IL-6 from fibroblasts, subsequently inducing tumor angiogenesis. IL-6R neutralization antibody inhibited IL-6 signaling and tumor angiogenesis by inhibiting the interaction between the cancer, and stroma. This finding suggests that IL-6 is a novel target for anti-angiogenesis therapy (44).

CAFs mediate tumor metastasis. Increasing evidence suggests a metastatic support role of CAFs in tumors $(45,46)$, whereas data regarding the presence and role of CAFs in lymph node and distant metastasis is deficient. Stromal reactions in metastatic lymph nodes, possibly comprising metastasis-associated fibroblasts, have been described as reactive and fibrotic tissue with enhanced deposition of vitronectin and fibronectin, desmoplasia, nodal fibrosis and hyaline stroma (47). Immunohistochemical characterization of CAFs was reported in one of these studies, which assessed metastatic lymph node tissue from a patient with uterine cervix adenocarcinoma who received preoperative chemotherapy (47). Certain studies have suggested that the mesenchymal-like phenotype of CAFs is involved in enhancing the metastasis of cancer cells, whereas NFs with the epithelial-like phenotype inhibit the migration of breast cancer cells (48). Similarly, normal prostate epithelial 
cells induce intraepithelial neoplasia in vivo when co-injected with CAFs, but not when co-injected with NFs (49).

YAP is a transcription factor that may be a signature feature of CAFs. YAP has important roles in matrix stiffening, cancer cell invasion and angiogenesis, which are induced by CAFs (50). YAP regulates the expression of specific cytoskeletal proteins, including anillin actin binding protein, diaphanous related formin 3 and myosin regulatory light polypeptide 9 (50). Additionally, CAFs secrete proinflammatory cytokines that stimulate the nuclear factor- $\kappa \mathrm{B}(\mathrm{NF}-\kappa \mathrm{B})$ signaling pathway, subsequently promoting tumorigenesis (51).

Notably, CAFs in the stroma of triple-negative breast cancer samples have been demonstrated to select for bone metastatic cells (52). CAFs produce CXCL12 and IGF1, which are prognostic markers for bone relapse and activators of the phosphatidylinositol 3-kinase (PI3K)/AKT serine/threonine kinase (AKT) signaling pathway (52). Cancer cells are primed for metastasis in the CXCL12-rich microenvironment of the bone marrow, thus suggesting an important role of CAFs in tumor metastasis. Another study demonstrated that a reduction in miR-148a expression in CAFs results in increased Wnt activity through the upregulation of its target gene WNT10B. Consequently, increased Wnt activity results in increased migration of endometrial cancer cells (53).

A study reported that the downregulation of miR-26b in CAFs stimulates the migration of fibroblasts, which is a dominant characteristic of the CAF phenotype. Furthermore, CAFs with reduced expression of miR-26b promote the migration and invasion of human breast cancer cells (54). Additionally, the PTEN/miR-320/ETS2 axis secretes proteins, such as Emilin2, that distinguish between normal and malignant stroma, and is associated with a higher rate of relapse in patients with breast cancer (55). This demonstrates that miR-320 is an essential regulator of the signaling pathway in fibroblasts involved in the regulation of the tumor microenvironment. Similar to in breast cancer, in prostate cancer, the downregulation of miR-15 and -16 in CAFs is mediated through activation of the AKT, and extracellular signal-regulated kinase signaling pathways, promoting prostate cancer migration, and angiogenesis (56).

CAFs induce resistance of cancer cells to therapy. Compared with cancer cells, CAFs are relatively genetically stable with a reduced probability of developing drug-resistance, thus representing as a potential therapeutic target with lower chances for the development of chemoresistance $(57,58)$. However, an increasing amount of data has suggested that fibroblasts have a protective role that allows cancer cells to evade therapy, as described below.

$P D G F$. The interstitial fluid pressure (IFP) in the center of solid tumors is increased compared with that in the surrounding tumor tissue (59). Higher IFP reduces the efficiency of drug penetration into the tumor tissue, thus reducing the concentration of the drug reaching the tumor cells and increasing tumor cell viability (58). Strategies on improving chemotherapy have focused on reducing tumor IFP in order to increase the efficiency of drug transport and penetration into tumors (60).

PDGF and other associated tyrosine kinase receptors are expressed in various types of cancer. STI571, a receptor tyrosine kinase inhibitor (TKI), reduces tumor IFP and increases Taxol uptake in subcutaneously injected undifferentiated anaplastic thyroid carcinoma KAT-4 cell line-induced transplantable tumors in severe combined immune deficient mice $(61,62)$.

$H G F$. HGF has been identified as an essential factor in of CAF-mediated resistance to B-Raf proto-oncogene serine/threonine kinase (BRAF) inhibitor therapy in melanoma with $\mathrm{BRAF}^{\mathrm{V} 600 \mathrm{E}}$ mutation, as well as lapatinib resistance in HER $2^{+}$breast cancer $(63,64)$.

TKIs exhibit strong inhibitory effects against NSCLC with epidermal growth factor receptor (EGFR)-activating mutations (65). However, the possibility of intrinsic or developing acquired resistance is an important consideration in the management of patients with cancer. The overexpression of HGF in CAF, a ligand of HGF receptor (MET), has been reported to contribute to resistance to EGFR-TKIs (66).

EGFR and HGF are coexpressed in colorectal cancer (CRC) cell lines, and the activation of both receptors synergistically induces the proliferation of cancer cells (67). Cetuximab suppresses cell growth through dephosphorylation of EGFR, mitogen-activated protein kinase (MAPK), and/or the AKT signaling pathway (68). It was demonstrated that CAF-derived HGF phosphorylates MET, but not EGFR or receptor tyrosine-protein kinase erbB-3 in cetuximab-treated cells. Subsequently, this was revealed to restore cell proliferation and rescue cells from $\mathrm{G}_{1}$ phase arrest, and apoptosis through restimulation of the MAPK and AKT signaling pathways (68). Notably, this effect is inhibited by suppressing MET activation with PHA-665752, a highly specific MET kinase inhibitor, or by knocking down MET expression using RNA interference (69).

Together, these data demonstrate that the presence of fibroblasts secreting HGF confers resistance to therapy. In addition, HGF can activate MET, which is expressed on cancer-initiating cells (CICs) in colon cancer, through paracrine signaling (70). This can sustain typical CIC properties, including long-term self-renewal, ultimately leading to resistance to anti-EGFR therapy (70).

Chemokines. Increasing evidence supports the presence of stromal cytokines that are important in the development of tumor chemoresistance.

CCL2 is an inflammatory chemokine, which is recruited by immune cells into the tumor microenvironment and has been demonstrated to confer resistance to paclitaxel, and docetaxel in prostate cancer (71). A previous study demonstrated that CCL2 expression is higher in three different paclitaxel-resistant ovarian cancer cell lines ES-2/TP, MES-OV/TP and OVCAR-3/TP compared with parental cells (72). Furthermore, treatment with a CCL2 inhibitor enhances the antitumor efficacy of paclitaxel and carboplatin combination therapy in ovarian cancer (72). CAFs can induce CCL2 production through signal transducer and activator of transcription 3 (STAT3) phosphorylation, and in turn, CAF-derived CCL2 promotes cancer progression by regulating cancer stem cells through activation of the Notch signaling pathway (73).

The chemokine CXCL12 is the sole ligand of CXCR4. CAFs are an important source of CXCL12 in the tumor stroma. Previous studies have indicated that CXCL12/CXCR4 
signaling contributes to chemoresistance by inducing the activation of focal adhesion kinase, ERK and AKT signaling pathways, enhancing the transcriptional activities of $\beta$-catenin, and $N F-\kappa B$, and the expression of survival proteins $(74,75)$. Disruption of the CXCR4/CXCL12 signaling pathway has been demonstrated to sensitize prostate cancer cells to docetaxel (76). Similar results have been observed in colon (77) and lung (78) cancer. Therefore, these studies suggest that chemokines, including CXCL12, may act as promising targets for cancer therapy, alone and/or in combination with other cytotoxic drugs.

Interleukin family. Emerging evidence suggests that the dynamic crosstalk between tumor cells and stromal fibroblasts underlie drug resistance. In CRC, IL-17A, which is overexpressed by CAFs in response to chemotherapy, bind to the IL-17A receptor expressed on CICs (79). Consequently, this results in the maintenance and development of therapeutic resistance of CICs through the upregulation of NF- $\mathrm{NB}$ (79). In ER-negative and triple-negative breast cancer, IL-17A protects from docetaxel-induced cell death through activation of ERK1, and 2, thus participating in therapy-resistance development (80).

IL-6, an inflammatory cytokine, is primarily secreted by CAFs. IL-6 promotes the growth and invasion of cancer cells through activation of STAT3 (81). NSCLC cells expressing persistently activated mutant EGFR are also associated with the IL-6 signaling pathway, which promotes the proliferation and survival of cells, leading to erlotinib resistance $(82,83)$. IL-6 secreted by CAFs induces tamoxifen resistance through activation of the Janus kinase (JAK)/STAT3 and PI3K/AKT signaling pathways in breast cancer cells (84). Inhibition of proteasome activity, IL-6 activity or the JAK/STAT3, or PI3K/AKT signaling pathways markedly reduced CAF-induced tamoxifen resistance (84). These results demonstrate that IL-6 creates a 'protective niche' that maintains the survival of residual tumor cells, consequently inducing tumor relapse.

Other factors. WNT16B is an important fibroblast-derived protein and treatment-induced factor that confers chemotherapy resistance. The chemotherapy resistance effects of fibroblast-derived WNT16B have been detected in vivo and in vitro, indicating that WNT16B reduces apoptosis induced by chemotherapy drugs in prostatic carcinoma (85). This study guides novel directions for combination therapies, including targeting fibroblast-derived WNT16B, which may reverse chemoresistance in breast and prostate cancer (85). Fibroblast-secreted high mobility group protein B1 is released into the tumor microenvironment and performs paracrine signaling on neighboring cancer cells, which has been suggested to induce chemoresistance in breast cancer (86).

\section{Interaction loop}

A bi-directional activation between cancer cells and fibroblasts has been identified as the leading cause of formation of the malignant phenotype of cancer. As aforementioned, the crosstalk between the two is important for tumor progression, and the interactions between them are induced by the reciprocal

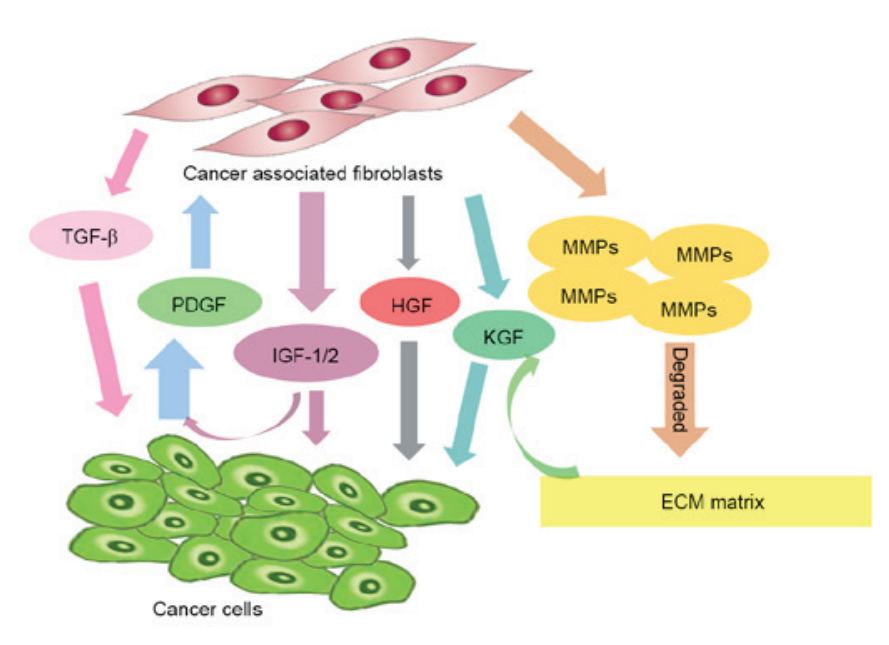

Figure 1. Cancer-induced fibroblast activation and cytokine release followed by cancer associated fibroblast-induced tumor growth, and metastasis resulting in a feedback loop. TGF- $\beta$, transforming growth factor $\beta$; PDGF, platelet-derived growth factor; IGF, IGF like family member; HGF, hepatocyte growth factor; KGF, keratinocyte growth factor; MMPs, matrix metalloproteinases; ECM, extracellular matrix.

signaling of secreted components, including cytokines, and regulatory factors in the ECM. Cullen et al (87) reported that cancer cells produce PDGF, which induces fibroblast proliferation and the expression of IGF I, and II. Notably, IGFs secreted by fibroblasts in turn induce cancer cell proliferation and the synthesis of PDGF (87).

Cancer cells induce the production of matrix metalloproteinases (MMPs) by fibroblasts, which results in degradation of the extracellular matrix and enhances the invasiveness of cancer cells (88). In return, fibroblasts secrete growth factors, including HGF (89), keratinocyte growth factor (90), and IGF-1 and -2 (91), which stimulate the proliferation of cancer cells. Furthermore, a previous study reported that local cell-cell interactions between breast cancer cells and fibroblasts exhibit various effects on numerous genes, including the regulation of the expression of TGF- $\beta$-altered genes (92).

These signaling pathways are involved in positive feedback loops, which result in increased tumor cell numbers and/or amplification of signaling molecules, and consequently tumor therapy resistance. Thus, understanding the biological mechanism underlying CAFs may aid in the development of novel molecular-targeted therapies to inhibit these signaling feedback loops (Fig. 1).

\section{Inhibition of the feedback loop as an approach for an- ti-cancer therapy}

In order to target CAFs, a possible approach is to inhibit the feedback loop between fibroblasts and cancer cells. Such therapies have not yet been applied clinically, but based on the aforementioned evidence, the potential benefits of these treatments have been demonstrated. Inhibiting the feedback loop may involve the following approaches: Inhibition of fibroblasts directly and disruption of CAF-associated paracrine growth factor signals (Fig. 2) (6). 


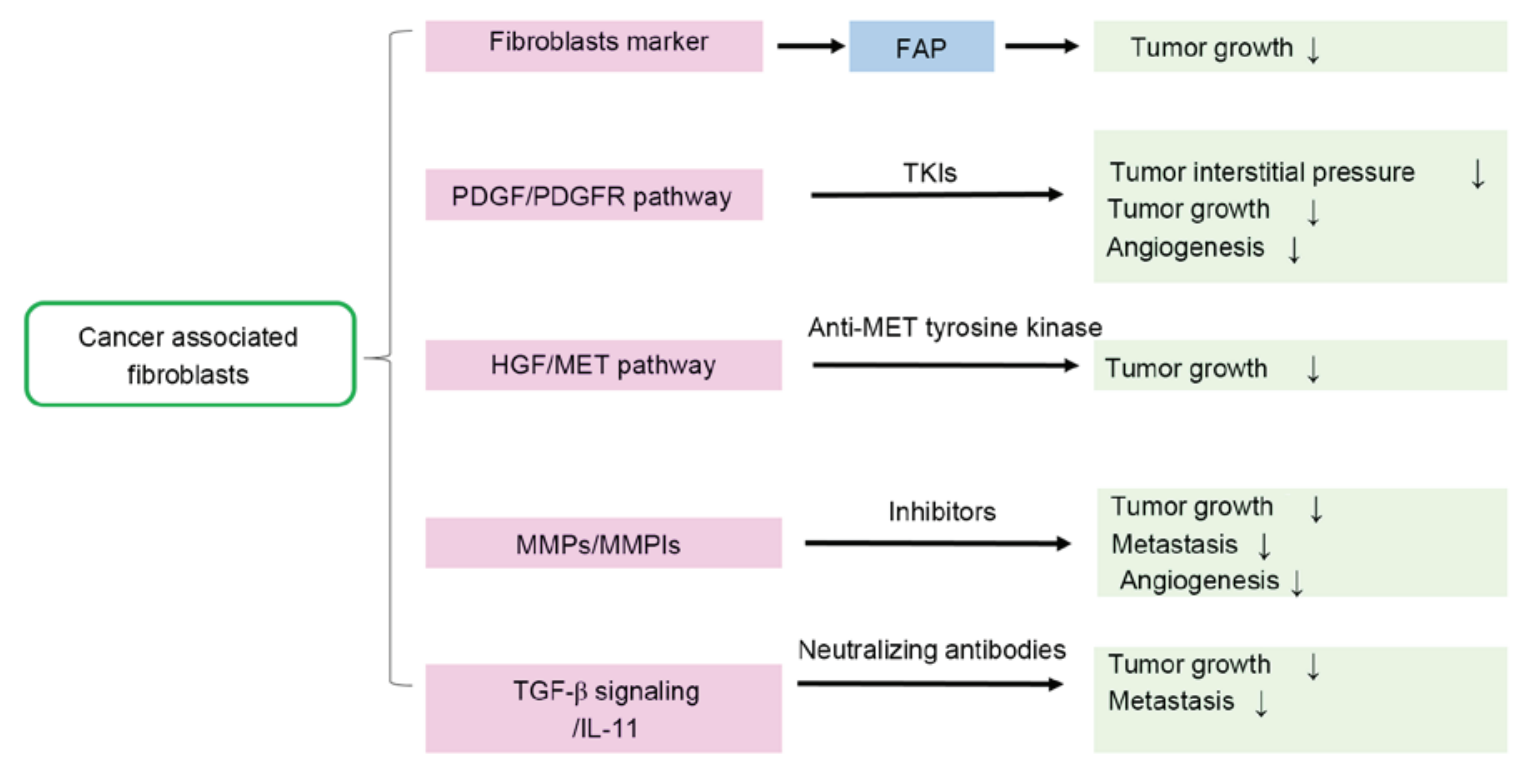

Figure 2. Therapeutic target markers and pathways of CAFs. This fig presents the potential strategies of inhibiting the feedback loop and targeting CAFs during malignant cancer treatment. CAFs, cancer-associated fibroblasts; TGF- $\beta$, transforming growth factor $\beta$; PDGF, platelet-derived growth factor; PDGFR, PDGF receptor; HGF, hepatocyte growth factor; MET, hepatocyte growth factor receptor; MMPs, matrix metalloproteinases; MMPIs, MMP inhibitors; TKIs, tyrosine kinase inhibitors; IL-11, interleukin-11; FAP, fibroblast activation protein.

Targeting fibroblast markers directly. Therapy directed at specific fibroblast markers or the antigens presented on CAFs make CAFs particularly sensitive to cancer treatment. FAP is a membrane protein that is exclusively overexpressed on CAFs (93). FAP has been shown to support tumor growth and proliferation, making it a potential target for novel anticancer therapies (94). FAP-specific molecules selectively target fibroblasts and finally inhibit the growth of surrounding cancer cells $(94,95)$.

FAP $\alpha$-specific monoclonal antibodies have demonstrated therapeutic potential in cancer treatment. FAP5-DM1, a monoclonal maytansinoid-conjugated antibody, was demonstrated to inhibit and cause the complete regression of tumor growth in xenograft models of lung, pancreatic, and head and neck cancer in vivo (96).

Inhibition of FAP $\alpha$ enzyme activity using specific inhibitors has also been considered a promising approach to targeting fibroblasts. Using the peptidase inhibitor, PT-100 (talabostat) was revealed to reduce the tumor growth rate in numerous types of tumor animal models (97). Knocking down FAP $\alpha$ expression resulted in distinct tumor growth regression in an $L S L-K-r{ }^{\mathrm{G} 12 \mathrm{D}}$ genetic mouse model of lung cancer and in a colon cancer model, suggesting a tumor-supporting role of endogenous FAP $\alpha$ (98). Furthermore, treatment with PT-630 was able to inhibit tumor growth in the lung and colon cancer models (98).

\section{Targeting paracrine signaling of fibroblasts}

PDGF/PDGFR signaling pathway. Cancers stimulate CAFs through the activation of PDGFR. A previous study demonstrated that following the overexpression of PDGF in cancer cells, there was an increase in the fibrotic stroma response, thus suggesting an essential role of PDGFR signaling in fibroblast activation (99).

Multiple TKIs, including imatinib, sorafenib and sunitinib, confer anti-PDGFR activity, and the association between TKIs and PDGFR activity is currently being investigated (100). Imatinib, is a breakpoint cluster region-ABL proto-oncogene 1 non-receptor tyrosine kinase inhibitor, which also exhibits anti-PDGFR and anti-c-kit kinase activity, resulting in decreased proliferation, and protein expression regulation in human colorectal fibroblasts (101). Furthermore, targeting PDGFRs increases the uptake and therefore the inhibitory effect of chemotherapeutics, including paclitaxel, by decreasing the IFP (62).

The indolinone derivative BIBF1120 is a potent inhibitor of VEGFR, PDGFR and FGFR family members. It has been revealed to inhibit MAPK and Akt signaling pathways in endothelial cells, pericytes, and smooth muscle cells, all of which contribute to angiogenesis, thus resulting in the inhibition of cancer cell proliferation and apoptosis. BIBF1120 has been applied clinically for the treatment of several types of tumor (102). Taken together, these findings suggest that the inhibition of PDGFR signaling may serve as a novel treatment approach for cancer.

HGF/MET signaling pathway. HGF is a growth factor that is primarily secreted by fibroblasts to activate c-Met on cancer cells (103). Genetic and biological studies have suggested that HGF and its receptor MET are potential targets for cancer treatment. The progress in understanding the structure and function of HGF/MET has led to the development of targeting drugs and numerous small molecule MET kinase inhibitors. Reports from previous clinical trails demonstrated that inhibiting MET signaling has great therapeutic value in several types of human cancers, including NSCLC $(104,105)$.

The use of the anti-HGF monoclonal antibodies AMG-102 (rilotumumab) and AV-299 (ficlatuzumab) has been investigated in previous clinical trials $(106,107)$. Furthermore, the anti-MET agents represent a novel strategy for the inhibition of the MET signaling pathway. Several phase I and II clinical trials have 
investigated the use of novel small molecules that target MET tyrosine kinase, including tivantinib (108), cabozantinib (109) and crizotinib (110-112). With the results of these translational and clinical studies, HGF/MET-targeted therapy is becoming a promising therapeutic choice for patients with NSCLC.

MMPs/MMP inhibitors (MMPIs). MMPs are primarily derived from CAFs in various types of tumor. MMPs have been extensively detected in animal model experiments, which have demonstrated the importance of these proteases in inducing tumor growth, metastasis and angiogenesis $(113,114)$. Inhibitors can be used to therapeutically target MMPs and lower the enzymatic activity, providing a prospective for future studies. Even though the majority of clinical trials on these drugs have reported insufficient results, research on MMPIs remains ongoing $(115,116)$. Considering these explanations, one of the major difficulties in the future is the development of inhibitors or antibodies that bind to the active site of the enzyme and are highly specific to certain MMPs (117).

TGF- $\beta$ signaling. TGF- $\beta$ stimulates myofibroblast differentiation and the inhibition of TGF- $\beta$ signaling in stromal fibroblasts result in significant regression in tumor growth; however, the antitumor effects of TGF- $\beta$ signaling may depend primarily on individual tumor models (118). The TGF- $\beta$ signaling pathway is increasingly considered as a therapeutic target due to its role in cancer cells and its capacity to instruct a protumorigenic program in tumor stromal cells (119). Several therapeutic agents that inhibit the TGF- $\beta$ signaling pathway have been studied in preclinical and clinical trials. Neutralizing antibodies, soluble receptors and antisense oligonucleotides that target the ligand-receptor interaction, and inhibit the function of TGFBRI or TGFBRII have been studied in clinical experiments (120). The clinical application of the TGFBRI kinase inhibitor LY2157299 has been investigated in glioblastoma (121), hepatocellular carcinoma (122) and advanced pancreatic cancer (123); these studies have provided promising results.

Crosstalk between cancer cells and CAFs through TGF- $\beta$ could suggest another therapeutic target. IL-11 has been recognized for its capacity to promote the maturation of platelets producing megakaryocyte progenitors in vitro and in the bone marrow in vivo (124). A previous study investigated the pro-metastatic effect of IL-11, which is secreted by TGF- $\beta$-stimulated CAFs in CRC (125). It was reported that IL-11 promotes the survival of tumor cells at the sites of metastatic colonization (125). This finding suggests that the clinical use of IL-11 to treat thrombocytopenia caused by chemotherapy agents should be reconsidered and the use of anti-IL11 therapies against CRC should be evaluated.

\section{Conclusion}

CAFs are considered as an essential component of tumorigenesis. Increasing evidence has suggested that CAFs exhibit a positive effect on the development of solid tumors. CAFs can modulate tumor microenvironment through diverse mechanisms, thus supporting tumor progression. Pre-clinical and clinical trials have revealed that CAFs are a potential target for the treatment of solid tumors.

\section{References}

1. Balkwill FR, Capasso M and Hagemann T: The tumor microenvironment at a glance. J Cell Sci 125: 5591-5596, 2012.

2. Hanahan D and Weinberg RA: The hallmarks of cancer. Cell 100: 57-70, 2000.

3. Spano D and Zollo M: Tumor microenvironment: A main actor in the metastasis process. Clin Exp Metastasis 29: 381-395, 2012.

4. Swartz MA, Iida N, Roberts EW, Sangaletti S, Wong MH, Yull FE, Coussens LM and DeClerck YA: Tumor microenvironment complexity: Emerging roles in cancer therapy. Cancer Res 72: 2473-2480, 2012.

5. Quail DF and Joyce JA: Microenvironmental regulation of tumor progression and metastasis. Nat Med 19: 1423-1437, 2013.

6. Cirri P and Chiarugi P: Cancer-associated-fibroblasts and tumour cells: A diabolic liaison driving cancer progression. Cancer Metast Rev 31: 195-208, 2012.

7. Marsh T, Pietras K and McAllister SS: Fibroblasts as architects of cancer pathogenesis. Biochim Biophys Acta 1832: 1070-1078, 2013.

8. Sun Y: Translational horizons in the tumor microenvironment: Harnessing breakthroughs and targeting cures. Med Res Rev 35: 408-436, 2015.

9. Slany A, Bileck A, Muqaku B and Gerner C: Targeting breast cancer-associated fibroblasts to improve anti-cancer therapy. Breast 24: 532-538, 2015.

10. Anderberg $\mathrm{C}$ and Pietras $\mathrm{K}$ : On the origin of cancer-associated fibroblasts. Cell Cycle 8: 1461-1462, 2009.

11. Liu Y, Hu T, Shen J, Li SF, Lin JW, Zheng XH, Gao QH and Zhou HM: Separation, cultivation and biological characteristics of oral carcinoma-associated fibroblasts. Oral Dis 12: 375-380, 2006.

12. Sugimoto H, Mundel TM, Kieran MW and Kalluri R: Identification of fibroblast heterogeneity in the tumor microenvironment. Cancer Biol Ther 5: 1640-1646, 2006.

13. Park JE, Lenter MC, Zimmermann RN, Garin-Chesa P, Old LJ and Rettig WJ: Fibroblast activation protein, a dual specificity serine protease expressed in reactive human tumor stromal fibroblasts. J Biol Chem 274: 36505-36512, 1999.

14. Kim HM, Jung WH and Koo JS: Expression of cancer-associated fibroblast related proteins in metastatic breast cancer: An immunohistochemical analysis. J Transl Med 13: 222, 2015.

15. Rupp C, Scherzer M, Rudisch A, Unger C, Haslinger C, Schweifer N, Artaker M, Nivarthi H, Moriggl R, Hengstschläger M, et al: IGFBP7, a novel tumor stroma marker, with growth-promoting effects in colon cancer through a paracrine tumor-stroma interaction. Oncogene 34: 815-825, 2015.

16. Navab R, Strumpf D, Bandarchi B, Zhu CQ, Pintilie M, Ramnarine VR, Ibrahimov E, Radulovich N, Leung L, Barczyk M, et al: Prognostic gene-expression signature of carcinoma-associated fibroblasts in non-small cell lung cancer. Proc Natl Acad Sci USA 108: 7160-7165, 2011.

17. Zhu CQ, Popova SN, Brown ER, Barsyte-Lovejoy D, Navab R, Shih W, Li M, Lu M, Jurisica I, Penn LZ, et al: Integrin alpha11 regulates IGF2 expression in fibroblasts to enhance tumorigenicity of human non-small-cell lung cancer cells. Proc Natl Acad Sci USA 104: 11754-11759, 2007.

18. Nakagawa H,Liyanarachchi S, Davuluri RV, Auer H, Martin EW Jr, de la Chapelle A and Frankel WL: Role of cancer-associated stromal fibroblasts in metastatic colon cancer to the liver and their expression profiles. Oncogene 23: 7366-7377, 2004.

19. Walter K, Omura N, Hong SM, Griffith M, Vincent A, Borges M and Goggins M: Overexpression of smoothened activates the sonic hedgehog signaling pathway in pancreatic cancer-associated fibroblasts. Clin Cancer Res 16: 1781-1789, 2010.

20. Rozenchan PB, Carraro DM, Brentani H, de Carvalho Mota LD, Bastos EP, e Ferreira EN, Torres CH, Katayama ML, Roela RA, Lyra EC, et al: Reciprocal changes in gene expression profiles of cocultured breast epithelial cells and primary fibroblasts. Int J Cancer 125: 2767-2777, 2009.

21. Kalluri R and Zeisberg M: Fibroblasts in cancer. Nat Rev Cancer 6: 392-401, 2006.

22. Räsänen K and Vaheri A: Activation of fibroblasts in cancer stroma. Exp Cell Res 316: 2713-2722, 2010.

23. Clayton A, Evans RA, Pettit E, Hallett M, Williams JD and Steadman R: Cellular activation through the ligation of intercellular adhesion molecule-1. J Cell Sci 111: 443-453, 1998.

24. Zhang B, Pan X, Cobb GP and Anderson TA: microRNAs as oncogenes and tumor suppressors. Dev Biol 302: 1-12, 2007. 
25. Mitra AK, Zillhardt M, Hua Y, Tiwari P, Murmann AE, Peter ME and Lengyel E: MicroRNAs reprogram normal fibroblasts into cancer-associated fibroblasts in ovarian cancer. Cancer Discov 2 : $1100-1108,2012$

26. Zhao L, Sun Y, Hou Y, Peng Q, Wang L, Luo H, Tang X, Zeng Z and Liu M: MiRNA expression analysis of cancer-associated fibroblasts and normal fibroblasts in breast cancer. Int J Biochem Cell Biol 44: 2051-2059, 2012.

27. Enkelmann A, Heinzelmann J, von Eggeling F, Walter M, Berndt A, Wunderlich $\mathrm{H}$ and Junker K: Specific protein and miRNA patterns characterise tumour-associated fibroblasts in bladder cancer. J Cancer Res Clin Oncol 137: 751-759, 2011.

28. Yu Z, Willmarth NE, Zhou J, Katiyar S, Wang M, Liu Y, McCue PA, Quong AA, Lisanti MP and Pestell RG: microRNA $17 / 20$ inhibits cellular invasion and tumor metastasis in breast cancer by heterotypic signaling. Proc Natl Acad Sci USA 107: 8231-8236, 2010

29. Aprelikova O, Yu X, Palla J, Wei BR, John S, Yi M, Stephens R, Simpson RM, Risinger JI, Jazaeri A and Niederhuber J: The role of miR-31 and its target gene SATB2 in cancer-associated fibroblasts. Cell Cycle 9: 4387-4398, 2014.

30. Wang S, Wang Z, Xu K, Ruan Z and Chen L: miRNA expression analysis of cancer-associated fibroblasts and normal fibroblasts in colorectal cancer. J Mod Oncol 09: 1918-1922, 2013.

31. Bhowmick NA, Neilson EG and Moses HL: Stromal fibroblasts in cancer initiation and progression. Nature 432 332-337, 2004

32. Gonda TA, Varro A, Wang TC and Tycko B: Molecular biology of cancer-associated fibroblasts: Can these cells be targeted in anti-cancer therapy? Seminars Cell Dev Biol 21: 2-10, 2009.

33. Ostman A and Augsten M: Cancer-associated fibroblasts and tumor growth-bystanders turning into key players. Curr Opin Genet Dev 19: 67-73, 2009.

34. Servais C and Erez N: From sentinel cells to inflammatory culprits: Cancer-associated fibroblasts in tumour-related inflammation. J Pathol 229: 198-207, 2013

35. Luker KE, Lewin SA, Mihalko LA, Schmidt BT, Winkler JS, Coggins NL, Thomas DG and Luker GD: Scavenging of CXCL12 by CXCR7 promotes tumor growth and metastasis of CXCR4-positive breast cancer cells. Oncogene 31: 4750-4758, 2012.

36. Augsten M, Sjöberg E, Frings O, Vorrink SU, Frijhoff J, Olsson E, Borg A and Östman A: Cancer-associated fibroblasts expressing CXCL14 rely upon NOS1-derived nitric oxide signaling for their tumor-supporting properties. Cancer Res 74 : 2999-3010, 2014.

37. Mi Z, Bhattacharya SD, Kim VM, Guo H, Talbot LJ and Kuo PC: Osteopontin promotes CCL5-mesenchymal stromal cell-mediated breast cancer metastasis. Carcinogenesis 32 477-487, 2011

38. Quante M, Tu SP, Tomita H, Gonda T, Wang SS, Takashi S, Baik GH, Shibata W, Diprete B, Betz KS, et al: Bone marrow-derived myofibroblasts contribute to the mesenchymal stem cell niche and promote tumor growth. Cancer Cell 19: 257-272, 2011

39. Li X, Xu Q, Wu Y, Li J, Tang D, Han L and Fan Q: A CCL2/ROS autoregulation loop is critical for cancer-associated fibroblasts-enhanced tumor growth of oral squamous cell carcinoma. Carcinogenesis 35: 1362-1370, 2014

40. Shibuya M and Claesson-Welsh L: Signal transduction by VEGF receptors in regulation of angiogenesis and lymphangiogenesis. Exp Cell Res 312: 549-560, 2006.

41. Gomes FG, Nedel F, Alves AM, Nör JE and Tarquinio SB: Tumor angiogenesis and lymphangiogenesis: Tumor/endothelial crosstalk and cellular/microenvironmental signaling mechanisms. Life Sci 92: 101-107, 2013.

42. Ferrara N: Pathways mediating VEGF-independent tumor angiogenesis. Cytokine Growth Factor Rev 21: 21-26, 2010.

43. Zhang J and Liu J: Tumor stroma as targets for cancer therapy. Pharmacol Ther 137: 200-215, 2013.

44. Nagasaki T, Hara M, Nakanishi H, Takahashi H, Sato M and Takeyama H: Interleukin-6 released by colon cancer-associated fibroblasts is critical for tumour angiogenesis: Anti-interleukin- 6 receptor antibody suppressed angiogenesis and inhibited tumour-stroma interaction. Br J Cancer 110: 469-478, 2014.

45. Karagiannis GS, Poutahidis T, Erdman SE, Kirsch R, Riddell RH and Diamandis EP: Cancer-associated fibroblasts drive the progression of metastasis through both paracrine and mechanical pressure on cancer tissue. Mol Cancer Res 10: $1403-1418,2012$
46. Pavlides S, Vera I, Gandara R, Sneddon S, Pestell RG, Mercier I, Martinez-Outschoorn UE, Whitaker-Menezes D, Howell A, Sotgia F and Lisanti MP: Warburg meets autophagy: Cancer-associated fibroblasts accelerate tumor growth and metastasis via oxidative stress, mitophagy, and aerobic glycolysis. Antioxid Redox Signal 16: 1264-1284, 2012.

47. De Wever O, Van Bockstal M, Mareel M, Hendrix A and Bracke M: Carcinoma-associated fibroblasts provide operational flexibility in metastasis. Semin Cancer Biol 25: 33-46, 2014

48. Dumont N, Liu B, DeFilippis RA, Chang H, Rabban JT, Karnezis AN, Tjoe JA, Marx J, Parvin B and Tlsty TD: Breast fibroblasts modulate early dissemination, tumorigenesis, and metastasis through alteration of extracellular matrix characteristics. Neoplasia 15: 249-262, 2013

49. Olumi AF, Grossfeld GD, Hayward SW, Carroll PR, Tlsty TD and Cunha GR: Carcinoma-associated fibroblasts direct tumor progression of initiated human prostatic epithelium. Cancer Res 59: 5002-5011, 1999.

50. Calvo F, Ege N, Grande-Garcia A, Hooper S, Jenkins RP, Chaudhry SI, Harrington K, Williamson P, Moeendarbary E, Charras G and Sahai E: Mechanotransduction and YAP-dependent matrix remodelling is required for the generation and maintenance of cancer-associated fibroblasts. Nat Cell Biol 15: 637-646, 2013.

51. Erez N, Truitt M, Olson P, Arron ST and Hanahan D Cancer-associated fibroblasts are activated in incipient neoplasia to orchestrate tumor-promoting inflammation in an NF-kappaB-dependent manner. Cancer cell 17: 135-147, 2010.

52. Zhang XH, Jin X, Malladi S, Zou Y, Wen YH, Brogi E, Smid M, Foekens JA and Massagué J: Selection of bone metastasis seeds by mesenchymal signals in the primary tumor stroma. Cell 154: 1060-1073, 2013

53. Aprelikova O, Palla J, Hibler B, Yu X, Greer YE, Yi M, Stephens R, Maxwell GL, Jazaeri A, Risinger JI, et al: Silencing of miR-148a in cancer-associated fibroblasts results in WNT10B-mediated stimulation of tumor cell motility. Oncogene 32: 3246-3253, 2013.

54. Verghese ET, Drury R, Green CA, Holliday DL, Lu X, Nash C, Speirs V, Thorne JL, Thygesen HH, Zougman A, et al: MiR-26b is down-regulated in carcinoma-associated fibroblasts from ER-positive breast cancers leading to enhanced cell migration and invasion. J Pathol 231: 388-399, 2013.

55. Bronisz A, Godlewski J, Wallace JA, Merchant AS, Nowicki MO, Mathsyaraja H, Srinivasan R, Trimboli AJ, Martin CK, Li F, et al: Reprogramming of the tumour microenvironment by stromal PTEN-regulated miR-320. Nat Cell Biol 14: 159-167, 2012.

56. Mongiat M, Marastoni S, Ligresti G, Lorenzon E, Schiappacassi M, Perris R, Frustaci S and Colombatti A: The extracellular matrix glycoprotein elastin microfibril interface located protein 2: A dual role in the tumor microenvironment. Neoplasia 12: 294-304, 2010.

57. Correia AL and Bissell MJ: The tumor microenvironment is a dominant force in multidrug resistance. Drug Resist Updat 15: 39-49, 2012.

58. Kerbel RS: A cancer therapy resistant to resistance. Nature 390: 335-336, 1997.

59. Swartz MA and Lund AW: Lymphatic and interstitial flow in the tumour microenvironment: Linking mechanobiology with immunity. Nat Rev Cancer 12: 210-219, 2012.

60. Khawar IA, Kim JH and Kuh HJ: Improving drug delivery to solid tumors: Priming the tumor microenvironment. J Control Release 201: 78-89, 2015.

61. Pietras K, Östman A, Sjöquist M, Buchdunger E, Reed RK, Heldin $\mathrm{CH}$ and Rubin K: Inhibition of Platelet-derived growth factor receptors reduces interstitial hypertension and increases transcapillary transport in tumors. Cancer Res 61: 2929-2934, 2001.

62. Pietras K, Rubin K, Sjöblom T, Buchdunger E, Sjöquist M, Heldin $\mathrm{CH}$ and Ostman A: Inhibition of PDGF receptor signaling in tumor stroma enhances antitumor effect of chemotherapy. Cancer Res 62: 5476-5484, 2002.

63. Wilson TR, Fridlyand J, Yan Y, Penuel E, Burton L, Chan E, Peng J, Lin E, Wang Y, Sosman J, et al: Widespread potential for growth-factor-driven resistance to anticancer kinase inhibitors. Nature 487: 505-509, 2012

64. Straussman R, Morikawa T, Shee K, Barzily-Rokni M, Qian ZR, Du J, Davis A, Mongare MM, Gould J, Frederick DT, et al: Tumour micro-environment elicits innate resistance to RAF inhibitors through HGF secretion. Nature 487: 500-504, 2012 . 
65. Paez JG, Jänne PA, Lee JC, Tracy S, Greulich H, Gabriel S, Herman P, Kaye FJ, Lindeman N, Boggon TJ, et al: EGFR mutations in lung cancer: Correlation with clinical response to gefitinib therapy. Science 304: 1497-1500, 2004.

66. Yano S, Wang W, Li Q, Yamada T, Takeuchi S, Matsumoto K, Nishioka Y and Sone S: HGF-MET in resistance to EGFR tyrosine kinase inhibitors in lung cancer. Curr Signal Trans Ther 6: 228-233, 2011.

67. Liska D, Chen CT, Bachleitner-Hofmann T, Christensen JG and Weiser MR: HGF rescues colorectal cancer cells from EGFR inhibition via MET activation. Clin Cancer Res 17: 472-482, 2011.

68. Yamatodani T, Ekblad L, Kjellén E, Johnsson A, Mineta H and Wennerberg J: Epidermal growth factor receptor status and persistent activation of Akt and p44/42 MAPK pathways correlate with the effect of cetuximab in head and neck and colon cancer cell lines. J Cancer Res Clin Oncol 135: 395402, 2009.

69. Liska D, Chen CT, Bachleitner-Hofmann T, Christensen JG and Weiser MR: HGF rescues colorectal cancer cells from EGFR inhibition via MET activation. Clin Cancer Res 17: 472-482, 2011.

70. Luraghi P, Reato G, Cipriano E, Sassi F, Orzan F, Bigatto V, De Bacco F, Menietti E, Han M, Rideout WM III, et al: MET signaling in colon cancer stem-like cells blunts the therapeutic response to EGFR inhibitors. Cancer Res 74: 1857-1869, 2014.

71. Qian DZ, Rademacher BL, Pittsenbarger J Huang CY Myrthue A, Higano CS, Garzotto M, Nelson PS and Beer TM: CCL2 is induced by chemotherapy and protects prostate cancer cells from docetaxel-induced cytotoxicity. Prostate 70: 433-442, 2010.

72. Moisan F, Francisco EB, Brozovic A, Duran GE, Wang YC, Chaturvedi S, Seetharam S, Snyder LA, Doshi P and Sikic BI: Enhancement of paclitaxel and carboplatin therapies by CCL2 blockade in ovarian cancers. Mol Oncol 8: 1231-1239, 2014.

73. Tsuyada A, Chow A, Wu J, Somlo G, Chu P, Loera S, Luu T, Li AX, Wu X, Ye W, et al: CCL2 mediates cross-talk between cancer cells and stromal fibroblasts that regulates breast cancer stem cells. Cancer Res 72: 2768-2779, 2012.

74. Weekes CD, Song D, Arcaroli J, Wilson LA, Rubio-Viqueira B, Cusatis G, Garrett-Mayer E, Messersmith WA, Winn RA and Hidalgo M: Stromal cell-derived factor $1 \alpha$ mediates resistance to mTOR-directed therapy in pancreatic cancer. Neoplasia 14 690-701, 2012

75. Singh S, Srivastava SK, Bhardwaj A, Owen LB and Singh AP: CXCL12-CXCR4 signalling axis confers gemcitabine resistance to pancreatic cancer cells: A novel target for therapy. Br J Cancer 103: 1671-1679, 2010

76. Domanska UM, Timmer-Bosscha H, Nagengast WB, Oude Munnink TH, Kruizinga RC, Ananias HJ, Kliphuis NM, Huls G, De Vries EG, de Jong IJ and Walenkamp AM: CXCR4 inhibition with AMD3100 sensitizes prostate cancer to docetaxel chemotherapy. Neoplasia 14: 709-718, 2012.

77. Heckmann D, Maier P, Laufs S, Wenz F, Zeller WJ, Fruehauf S and Allgayer H: CXCR4 expression and treatment with SDF-1 $\alpha$ or plerixafor modulate proliferation and chemosensitivity of colon cancer cells. Transl Oncol 6: 124-132, 2013.

78. Burger JA, Stewart DJ, Wald O and Peled A: Potential of CXCR4 antagonists for the treatment of metastatic lung cancer. Expert Rev Anticancer Ther 11: 621-630, 2011.

79. Lotti F, Jarrar AM, Pai RK, Hitomi M, Lathia J, Mace A, Gantt GA Jr, Sukhdeo K, DeVecchio J, Vasanji A, et al: Chemotherapy activates cancer-associated fibroblasts to maintain colorectal cancer-initiating cells by IL-17A. J Exp Med 210: 2851-2872,2013.

80. Cochaud S, Giustiniani J, Thomas C, Laprevotte E, Garbar C, Savoye AM, Curé H, Mascaux C, Alberici G, Bonnefoy N, et al: IL-17A is produced by breast cancer TILs and promotes chemoresistance and proliferation through ERK1/2. Sci Rep 3: 3456, 2013.

81. Studebaker AW, Storci G, Werbeck JL, Sansone P, Sasser AK Tavolari S, Huang T, Chan MW, Marini FC, Rosol TJ, et al: Fibroblasts isolated from common sites of breast cancer metastasis enhance cancer cell growth rates and invasiveness in an interleukin-6-dependent manner. Cancer Res 68: 9087-9095, 2008.

82. Gao SP, Mark KG, Leslie K, Pao W, Motoi N, Gerald WL, Travis WD, Bornmann W, Veach D, Clarkson B and Bromberg JF: Mutations in the EGFR kinase domain mediate STAT3 activation via IL-6 production in human lung adenocarcinomas. J Clin Invest 117: 3846-3856, 2007
83. Yao Z, Fenoglio S, Gao DC, Camiolo M, Stiles B, Lindsted T, Schlederer M, Johns C, Altorki N, Mittal V, et al: TGF-beta IL-6 axis mediates selective and adaptive mechanisms of resistance to molecular targeted therapy in lung cancer. Proc Natl Acad Sci USA 107: 15535-15540, 2010.

84. Sun X, Mao Y, Wang J, Zu L, Hao M, Cheng G, Qu Q, Cui D, Keller ET, Chen X, et al: IL-6 secreted by cancer-associated fibroblasts induces tamoxifen resistance in luminal breast cancer. Oncogene: doi: 10.1038/onc.2014.158.

85. Sun Y, Campisi J, Higano C, Beer TM, Porter P, Coleman I, True L and Nelson PS: Treatment-induced damage to the tumor microenvironment promotes prostate cancer therapy resistance through WNT16B. Nat Med 18: 1359-1368, 2012.

86. Amornsupuk K, Insawang T, Thuwajit P, O-Charoenrat P, Eccles SA and Thuwajit C: Cancer-associated fibroblasts induce high mobility group box 1 and contribute to resistance to doxorubicin in breast cancer cells. BMC Cancer 14: 955, 2014.

87. Cullen KJ, Smith HS, Hill S, Rosen N and Lippman ME: Growth factor messenger RNA expression by human breast fibroblasts from benign and malignant lesions. Cancer Res 51: 4978-4985, 1991

88. Shay G, Lynch CC and Fingleton B: Moving targets: Emerging roles for MMPs in cancer progression and metastasis. Matrix Biol 44-46: 200-206, 2015

89. Jia CC, Wang TT, Liu W, Fu BS, Hua X, Wang GY, Li TJ, Li X, Wu XY, Tai Y, et al: Cancer-associated fibroblasts from hepatocellular carcinoma promote malignant cell proliferation by HGF secretion. PLoS One 8: e63243, 2013.

90. Lin J, Liu C, Ge L, Gao Q, He X, Liu Y, Li S, Zhou M, Chen Q and Zhou H: Carcinoma-associated fibroblasts promotes the proliferation of a lingual carcinoma cell line by secreting keratinocyte growth factor. Tumor Biol 32: 597-602, 2011.

91. Weroha SJ and Haluska P: The insulin-like growth factor system in cancer. Endocrinol Metab Clin North Am 41: 335-350. vi, 2012.

92. Hawinkels LJ, Paauwe M, Verspaget HW, Wiercinska E, van der Zon JM, van der Ploeg K, Koelink PJ, Lindeman JH, Mesker W, ten Dijke P and Sier CF: Interaction with colon cancer cells hyperactivates TGF- $\beta$ signaling in cancer-associated fibroblasts. Oncogene 33: 97-107, 2014.

93. Mueller MM and Fusenig NE: Friends or foes-bipolar effects of the tumour stroma in cancer. Nat Rev Cancer 4: 839-849, 2004

94. Liu R, Li H, Liu L, Yu J and Ren X: Fibroblast activation protein: A potential therapeutic target in cancer. Cancer Biol Ther 13: 123-129, 2012.

95. LeBeau AM, Brennen WN, Aggarwal S and Denmeade SR: Targeting the cancer stroma with a fibroblast activation protein-activated promelittin protoxin. Mol Cancer Ther 8: 1378-1386, 2009.

96. Ostermann E, Garin-Chesa P, Heider KH, Kalat M, Lamche H, Puri C, Kerjaschki D, Rettig WJ and Adolf GR: Effective immunoconjugate therapy in cancer models targeting a serine protease of tumor fibroblasts. Clin Cancer Res 14: 4584-4592, 2008

97. Adams S, Miller GT, Jesson MI, Watanabe T, Jones B and Wallner BP: PT-100, a small molecule dipeptidyl peptidase inhibitor, has potent antitumor effects and augments antibody-mediated cytotoxicity via a novel immune mechanism. Cancer Res 64: 5471-5480, 2004.

98. Santos AM, Jung J, Aziz N, Kissil JL and Puré E: Targeting fibroblast activation protein inhibits tumor stromagenesis and growth in mice. J Clin Invest 119: 3613-3625, 2009.

99. Heldin $\mathrm{CH}$ : Targeting the PDGF signaling pathway in tumor treatment. Cell Commun Signal 11: 97, 2013.

100. Steeghs N, Nortier JW and Gelderblom H: Small molecule tyrosine kinase inhibitors in the treatment of solid tumors: An update of recent developments. Ann Surg Oncol 14: 942-953, 2007.

101. Pietras K, Pahler J, Bergers G and Hanahan D: Functions of paracrine PDGF signaling in the proangiogenic tumor stroma revealed by pharmacological targeting. PLos Med 5: e19, 2008.

102. Hilberg F, Roth GJ, Krssak M, Kautschitsch S, Sommergruber W, Tontsch-Grunt U, Garin-Chesa P, Bader G, Zoephel A, Quant J, et al: BIBF 1120: Triple angiokinase inhibitor with sustained receptor blockade and good antitumor efficacy. Cancer Res 68: 4774-4782, 2008.

103. Cecchi F, Rabe DC and Bottaro DP: Targeting the $\mathrm{HGF} / \mathrm{Met}$ signaling pathway in cancer therapy. Expert Opin Ther Targets 16: 553-572, 2012.

104. Gherardi E, Birchmeier W, Birchmeier C and Vande Woude G: Targeting MET in cancer: Rationale and progress. Nat Rev Cancer 12: 89-103, 2012. 
105.Sadiq AA and Salgia R: MET as a possible target for non-small-cell lung cancer. J Clin Oncol 31: 1089-1096, 2013.

106. Oliner KS, Tang R, Anderson A, et al: Evaluation of MET pathway biomarkers in a phase II study of rilotumumab (R, AMG 102) or placebo (P) in combination with epirubicin, cisplatin and capecitabine (ECX) in patients (pts) with locally advanced or metastatic gastric $(\mathrm{G})$ or esophagogastric junction (EGJ) cancer. In: J Clin Oncol Amer Soc Clin Oncol 2318 Mill Road, Ste 800, Alexandria, Va 22314 USA, 2012.

107. Tan E, Park K, Lim WT, et al: Phase 1b study of ficlatuzumab (AV-299), an anti-hepatocyte growth factor monoclonal antibody, in combination with gefitinib in Asian patients with NSCLC. J Clin Oncol 29 (Suppl): 493S, 2011.

108. Katayama R, Aoyama A, Yamori T, Qi J, Oh-hara T, Song Y Engelman JA and Fujita N: Cytotoxic activity of tivantinib (ARQ 197) is not due solely to c-MET inhibition. Cancer Res 73: 3087-3096, 2013.

109. Wakelee H, Gettinger S, Engelman J, et al: A phase Ib/II study of XL184 (BMS 907351) with and without erlotinib (E) in patients (pts) with non-small cell lung cancer (NSCLC). In: ASCO Annual Meeting Proceedings, pp3017, 2010.

110. Tanizaki J, Okamoto I, Okamoto K, Takezawa K, Kuwata K, Yamaguchi $\mathrm{H}$ and Nakagawa K: MET tyrosine kinase inhibitor crizotinib (PF-02341066) shows differential antitumor effects in non-small cell lung cancer according to MET alterations. J Thorac Oncol 6: 1624-1631, 2011.

111. Feng Y, Thiagarajan PS and Ma PC: MET signaling: Novel targeted inhibition and its clinical development in lung cancer. J Thorac Oncol 7: 459-467, 2012.

112. Blumenschein GR Jr, Mills GB and Gonzalez-Angulo AM: Targeting the hepatocyte growth factor-cMET axis in cancer therapy. J Clin Oncol 30: 3287-3296, 2012.

113. Egeblad M and Werb Z: New functions for the matrix metalloproteinases in cancer progression. Nat Rev Cancer 2: 161-174, 2002.

114. Rundhaug JE: Matrix metalloproteinases and angiogenesis. J Cell Mol Med 9: 267-285, 2005

115.Pavlaki $\mathrm{M}$ and Zucker S: Matrix metalloproteinase inhibitors (MMPIs): The beginning of phase I or the termination of phase III clinical trials. Cancer Metastasis Rev 22: 177-203, 2003.
116. Shepherd FA, Giaccone G, Seymour L, Debruyne C, Bezjak A, Hirsh V, Smylie M, Rubin S, Martins H, Lamont A, et al: Prospective, randomized, double-blind, placebo-controlled trial of marimastat after response to first-line chemotherapy in patients with small-cell lung cancer: A trial of the national cancer institute of Canada-clinical trials group and the European organization for research and treatment of cancer. J Clin Oncol 20: 4434-4439, 2002.

117. Konstantinopoulos PA, Karamouzis MV, Papatsoris AG and Papavassiliou AG: Matrix metalloproteinase inhibitors as anticancer agents. Int J Biochem Cell Biol 40: 1156-1168, 2008.

118. Bierie B and Moses HL: TGF- $\beta$ and cancer. Cytokine Growth Factor Rev 17: 29-40, 2006

119. Lonning S, Mannick J and McPherson J: Antibody targeting of TGF- $\beta$ in cancer patients. Curr Pharm Biotechnol 12: 2176-2189, 2011

120. Hawinkels LJ and Ten Dijke P: Exploring anti-TGF- $\beta$ therapies in cancer and fibrosis. Growth Factors 29: 140-152, 2011.

121. Rodon J, Carducci MA, Sepulveda-Sánchez JM, Azaro A, Calvo E, Seoane J, Braña I, Sicart E, Gueorguieva I, Cleverly AL, et al: First-in-human dose study of the novel transforming growth factor- $\beta$ receptor I kinase inhibitor LY2157299 monohydrate in patients with advanced cancer and glioma. Clin Cancer Res 21: 553-560, 2015.

122. Rani B, Dituri F, Cao Y, Engström U, Lupo L, Dooley S, Moustakas A and Giannelli G: P0320: Targeting TGF-beta I with the transforming growth factor receptor type I kinase inhibitor, LY2157299, modulates stemness-related biomarkers in hepatocellular carcinoma. J Hepatol 62: S429, 2015.

123. Whatcott CJ, Dumas SN, Watanabe A, LoBello J, Von Hoff DD and Han H: Abstract 2135: TGF $\beta$ RI inhibition results in reduced collagen expression in pancreatic ductal adenocarcinoma. Cancer Res: DOI: $10.1158 / 1538-7445$.

124. Johnstone CN, Chand A, Putoczki TL and Ernst M: Emerging roles for IL-11 signaling in cancer development and progression: Focus on breast cancer. Cytokine Growth Factor Rev 26: 489-498, 2015

125. Calon A, Espinet E, Palomo-Ponce S, Tauriello DV, Iglesias M, Céspedes MV, Sevillano M, Nadal C, Jung P, Zhang XH, et al: Dependency of colorectal cancer on a TGF- $\beta$-driven program in stromal cells for metastasis initiation. Cancer Cell 22: 571-584, 2012. 